\title{
The Impact of Rising of MOOCs on the Moral Education of Traditional Universities
}

\author{
Shanhai ZHANG \\ Zaozhuang Normal University \\ Zaozhuang 277100
}

\begin{abstract}
The rise of MOOCs, based on Internet technology, has brought subversive influences on traditional higher education, and also brought challenges to traditional moral education in college. In particular, MOOCs in English advocate multi-values, with the characteristics of cultural aggression and western colors. The values are conflict with traditional Chinese morality and socialist core values, which have a negative impact on young students. Based on this, the author believes that China's traditional colleges and universities should establish a MOOCs platform with independent intellectual property rights, effectively promote and disseminate Chinese traditional culture and socialist core values for young scholars, and promote the construction of moral education culture in colleges and universities.
\end{abstract}

Keywords-MOOCs; Traditional higher education; Moral education

\section{INTRODUCTION}

In 2012, MOOCs, "This near-stupid and high-sounding acronym, Mass Open Online Course (MOOC), encompasses a whole new, shocking, and potentially good way for cashstrapped students to learn online courses." [1] With specific characteristics not owned by modern universities, MOOCs have revolutionary challenges to modern higher education and have aroused widespread concern around the world. Some scholars compare MOOCs to "a digital tsunami" in the history of education. Therefore, Times Magazine calls 2012 the year of MOOCs.

MOOCs (i.e. the Massive Open Online Course) is a new teaching mode based on Internet technology. In 2008, the term "MOOCs" [2] was first proposed by scholars David Cormier and Bryan Alexander from the University of Prince Edward Island, Canada. In the same year, the first MOOCs course, 'Connectionism and Connectionist Knowledge', was launched, with 2,300 participants around the world taking the course free of charge. Compared with the traditional online courses, MOOCs aims to provide more free learning opportunities for more people, more emphasis on the openness and mass student size; compared with the traditional open educational resources, it pays more attention to the social interaction in the teaching process and learning activities, and is a new form of online teaching. But it was in 2011, when Sebastian Sloan, a professor at Stanford University, posted his graduate-level artificial intelligence course on the Internet that MOOCs really took off and attracted some 160,000 students from more than 190 different countries to sign up. Then the rapid expansion of MOOCs has raised business interest from investors and cashrich big companies planning to enter the higher education market. They collaborated with top universities to launch MOOC platforms, including Coursera, Udacity, EDX, etc. Now, the above three MOOC platforms have received ten millions of investment support, and nearly 100 courses have been launched, providing more students with the possibility of choosing first-class courses of first-class universities and learning systematically, and more and more universities are joining the practice of MOOC courses in various forms. Currently, there are more than 400 courses on the platform of Coursera with 4 million students, 60 and 30 courses respectively on EDX and Udacity with 1.75 million students [3].

At present, there are dozens of countries in the world actively promoting MOOCs, including the United States, the United Kingdom, Japan, Australia, Brazil, China and so on, with more than 6 million participants from more than 220 countries around the world. In May. 2013, Peking University and Tsinghua University announced one after another to join the MOOCs organization EDX jointly established by MIT and Harvard University, and began to prepare the massive online open course - MOOCs. On Jul. 8, Fudan University and Shanghai Jiaotong University signed a partnership agreement with Coursera to join the platform. So far, China's top universities have joined the U.S. "Troika" in offering online courses around the world. On Jul. 25th, DeTao Group donated RMB 5 million to Peking University to jointly carry out the research and development of "massive open online courses", and devoted itself to building the MOOCs curriculum system synchronized with the world, promoting the popularization and development of China's online open courses, and opening up the attempt of MOOCs localization.

MOOCs organized and led by Stanford University, Princeton University, University of Michigan, Massachusetts Institute of Technology, Harvard University and the University of California, Berkeley, and other top American elite universities sweeps across the globe. The impact on traditional higher education can be described in word of "shock", bringing disruptive changes to traditional higher education. It breaks the traditional fence of universities and enables those who cannot accept the university education to study university courses without barriers and promotes the equality of educational opportunities; at the same time, some famous universities also feels pressure in front of MOOCs; the educational idea of 
MOOCs is advocating lifelong education and lifelong learning. It focuses not only on early adult learners (college students), but also on lifelong learners (senior workers); for teachers, the indoctrination education mode of single-handedly learning and inherited from generation to generation, is becoming increasingly unusable for students; how to act as a course host, organize a teaching team, design the teaching resources, carry out personalized real-time online interaction, etc. has put forward new requirements for teachers.

The MOOCs brings impact on traditional higher education, so that higher education is urgently required to be revolutionized. Therefore, Zhen HUANG, vice president of Shanghai Jiaotong University, said: "If universities do not reform, they may descend to the teaching laboratories and guidance classrooms of first-class universities." Faced with the impact, many experts and scholars have put forward scientific measures to deal with it. What we should pay attention to today is that MOOCs as a completely new curriculum model or education model, what impact will it have on the moral education of traditional higher education? How should Chinese traditional higher education face it?

\section{THE IMPACT OF MOOCS ON THE MORAL EDUCATION OF TRADITIONAL CHINESE HIGHER EDUCATION}

Relevant research shows us, currently in China, the learners of "MOOCs" are mainly full-time students, "Specifically, the students with a junior college degree or above account for $80 \%$ and ones with an undergraduate degree account for over $50 \%$." [4] We know that the fundamental task of socialist universities is to educate people, teach and educate people, and train college students to become qualified builders and reliable successors to the cause of socialism with Chinese characteristics. Originated from western countries, "MOOCs", as a completely new mode of curriculum teaching, shoulders the tasks of both teaching knowledge and cultivating people's morality. Although Chinese universities are also striving to build MOOCs platforms that keep pace with the world, but the high-qualified courses offered in three MOOCs platforms set up by the world's top universities are irresistibly attractive to Chinese students because of their early establishment, rich and diverse curriculum and focus on free university-level education. They take the same course with ten millions of students from all over the world, watch carefully crafted videos from a team of teachers, actively discuss with teachers and students in lively discussion forums, and sometimes invite teaching assistants to provide feedback and necessary reminders about students' discussions and problems. The participants of some Coursera chat online using Google Hangouts on Air Weeklyvideo, Twitterfeed Facebookpage, create online classrooms, share learning experiences, and exchange views [5]. "They can have a positive impact on both profession and talents" [6], But it is undeniable that, most of the designers (teachers and their teams) of MOOCs come from the developed capitalist countries, and students are from all over the world. Some of their values and world outlook are opposite to China's traditional morality and socialist core values, which will inevitably have a negative impact on China's MOOCs students, especially college students. We think that the following aspects are worthy of attention:

\section{A. MOOCs suspected of cultural aggression}

Developed countries represented by the United States, under the slogan of "democratization of education", take advantage of the recently popular MOOCs to develop online education courses on a large scale, providing a utopian vision of education in low-lying areas around the world: Expand highquality education globally and provide high-quality higher education for all learners. But whether MOOCs, the cultural and educational product based on the developed countries, especially the United States, will accumulate into a wave of "educational and cultural neocolonialism" in the process of transferring educational resources to the poor education lowlying areas?

This concern is by no means superfluous. As we know, although MOOCs in elite Western universities strive to provide customized learning contents for different users around the world, most of the teaching videos and materials provided by professors in MOOCs, as well as discussions in the discussion boards, are mostly presented in English. Critics believe that the students from non-English speaking countries have to study English desperately, which has once again made the English language learning popular, so as to complete MOOCs. This kind of MOOCs, which must be taught through English learning, in fact puts English above the native language, making English a de facto second or quasi-national language, which is a denial of the linguistic rights of the native people to some extent, and also one of the characteristics of the colonial culture.

Language is the spiritual foundation of a country, a nation, it contains a country's history and culture, customs, values and beliefs and spiritual support, once the language or the feeling of language is lost, then a country, a nation's matrix will disintegrate, which will lead to the disaster of the whole country and nation. The hegemony of language often means the hegemony of information and culture.

"If they want to democratize education, it's certainly a good goal, but you also need to move to a different democracy and see what they want," said Lenny Gunawardana, a professor of educational technology at the University of New Mexico. Therefore, the MOOCs courses presented in English, which are suspected of cultural aggression and divorced from the local reality of our country, need to focus on global learners. It is wrong to think that everyone who chooses MOOCs speaks English and that everyone shares same priorities in life.

\section{B. The Conflict between Eastern and Western Values under MOOCs}

According to education statistics released recently on the website of the Ministry of Education, China had 24 million college students as of 2012. With a large population, Chinese students have long admired high-quality education in famous schools overseas, especially in Europe and the United States. Students with good condiitons have chosen to go abroad for further study. According to the 2013 Overseas Studying Trend Report jointly released by China Education Online and Overseas Studying Supervision Service Network, the number of Chinese students studying abroad has increased dramatically since the 21 st century with the development of economic 
globalization and the improvement of China's economic conditions. But there are many students who admire famous European and American schools and have no chance to study abroad. With MOOCs established, they have registered to take MOOCs published by Coursera, Udacity and EDX, which are based on American cultural background and American values. They hope to complete MOOCs courses in famous schools in order to obtain certificates from US famous schools etc.

The MOOCs teachers' team of elite schools in the West have designed courses for millions of students all over the world. Through more interaction between teachers and students and between students, the MOOCs have cultivated the students' open consciousness, efficiency concept and global vision values, and enhanced the concept of treating others and treating themselves as equals. It has changed the inherent narrowmindedness of traditional thinking, is conducive to cultivate students' divergent thinking, and expand students' thinking; MOOCs break the traditional teaching concept in terms of time and space, expand the communication space, so that people of different regions, different status, different nationalities, different ages can communicate and exchange freely, democratically and equally, and MOOCs also effectively expand the scope of students' communication, make students change the value attitude of life meaning in reality, so as to establish the correct values.

However, it is undeniable that when the western elite universities promote MOOCs, because of their openness and sharing, the rotten outlook on life and values of the western bourgeoisie, which go against the socialist core values, will prevail on MOOCs, and bring some negative impact on the value orientation of MOOCs Chinese students. (1) The MOOCs is spread in China, Chinese registered students in the long-term learning are easy to admire and even approve the Western lifestyle, moral, political views, economic ideas, which not only weakens the traditional morality of college students, but also weakens the national consciousness of college students. (2) The three dominant MOOCs platforms of in the United States constantly transmit cultural information to the global university students to affect the ideological front of the developing countries through their MOOCs. College students are in the period of rebellious psychology and pursuit of novel ideas, which is easy to be misled by these ideas, thus losing their due ideological and political concept and consciousness.

\section{UNDER EFFECT OF MOOCS, THE MORAL EDUCATION COUNTERMEASURE OF TRADITIONAL HIGHER EDUCATION}

In the face of the disruptive impact of MOOCs on traditional higher education, some scholars have a pessimistic view of traditional higher education. In Oct. 2012, Time magazine published the article "University is Dead, University Forever!" In the article, it proposed that "What's going to happen tomorrow? It's likely to be very selective--physical universities will continue to thrive, the best universities will continue to offer services that online education can't cover, while middle, expensive, for-profit universities will face tremendous pressure. So American Interest magazine predicted in early 2013 that "within the next 50 years, 4,500 universities in the United States will disappear by half."
In the short run, we may overestimate the impact of MOOCs on the traditional higher education model, so other scholars have a gentle judgment on the shock caused by MOOCs, that MOOCs cannot replace the traditional higher education at this stage, after all, the experience of campus life, the edification of campus culture cannot be replaced by online courses. However, the rise of MOOCs has brought about the globalization and popularization of high-quality higher educational resources, which will profoundly change the competitive mode of traditional higher education. Therefore, the author believes that traditional higher education should actively participate in and integrate into this reform in the rapid development of MOOCs, in order to turn the crisis into opportunity. In moral education, the traditional higher education should do the following work well.

\section{A. Learn from the experience of International MOOCs to create independently innovated online education system}

Domestic top universities have successively signed MOOCs in the United States, and some experts believe that it is meaningful but not a long-term solution. "It is not a state strategy to load Chinese language courses only on immature platforms in the United States, that is, to load Chinese goods onto a truck in the United States to allow students from Chinese-speaking backgrounds to learn Chinese." [9]. Based on the accumulated results of online education over the years, combined with the characteristics of education reform in Greater China, it is urgent to establish independently innovated MOOCs platform. Yiyi CHEN, a vice president of Tongji University, believes that "The shortest answer is doing". Therefore, Peking University and Tedao Group have cooperated in the research and development of "massive open online courses" in Jul. 2013, which has opened up the attempt of localization of MOOCs. At the same time, "Peking University, Tsinghua University, Fudan University, Zhejiang University, Nanjing University and other 12985 project colleges and universities" jointly announced to create an "online open courses" sharing platform, in order to promote massive online education, which can be seen as a high-profile manifesto of the localization of MOOCs practice.

In summary, the demand for localization of MOOCs has gained momentum, but many of these early efforts can only be seen as the germination of the Chinese version of MOOCs [10], and it will take time for localized MOOCs to truly provide massive, open and online learning.

The MOOCs with independent intellectual property rights is the battlefield to educate the ideological value of college students in higher education in China, to cultivate students' healthy personality and correct emotions, attitudes, and spread socialist core values.

\section{B. Pay Attention to Cultivating the Correct MOOCs Value of the College Students}

Massive online education is an open education facing the whole world. It is good to lay emphasis on learning from the MOOCs of elite universities in the West and share the excellent educational resources in the West, but many courses come along with the ideological concept or the personal value of the 
lecturers. The curriculum will inevitably involve the western bourgeoisie, and the western rotten lifestyle, moral concepts and values will unwittingly erode and distort the hearts of young students. Some courses try to preach the superiority of bourgeois culture and capitalism, weaken the culture and traditional morality of other nations, and make students produce national nihilism.

Faced with the impact of MOOCs, students have the right to choose courses, but for young students with insufficient cultural judgment and discrimination, it is obvious that they cannot be left unguided and laissez-faire. The lack or weakening of moral education will affect the implementation of the policy of higher education and the realization of the goal of higher education in China. Hence, the colleges and universities should strengthen the ideological education of college students, in addition to learning advanced science and culture, but also abandon the backward and vulgar value orientation. At the same time, we can use the three western platforms of MOOCs and China's MOOCs platform with independent intellectual property rights to promote and spread Chinese traditional culture and socialist core values.

\section{CONCLUSION}

In a word, colleges and universities are the key places to cultivate young students' moral thoughts and behaviors. With the rapid development of socialist education in contemporary China, we should correctly guide young students to understand the world and recognize themselves with the scientific outlook on development; The use of effective educational means will enable young college students to establish a correct life outlook, value outlook, world outlook, stimulate their patriotic emotion and behaviors to serve the country, and promote the national civilization construction and the healthy development of society.

\section{ACKNOWLEDGMENT}

Shanhai ZHANG, 1967-, male, Han nationality, native of Zaozhuang, Shandong, associate professor of Primary Education College of Zaozhuang University, Master of Management, Beijing Normal University, research direction: university moral education, university management and so on.

Mailing address: Primary Education College, Zaozhuang University, No. 61, Middle Chengshui Road, Yicheng District, Zaozhuang City, Shandong Province, China 277100.

\section{REFERENCES}

[1] http://edu.sina.com.cn/en/2013-03-05/105572647_2.shtml

[2] Manli LI. Analysis of the Characteristics and Instructional Design Principles of MOOCs [J]. Educational Research of Tsinghua University, 2013, 34 (4).

[3] Larry Johnson. Samantha Adamsbecker. Xiaojing BAI. Shengbo LI Questions about "MOOCs"--Social Repercussions of the Online Learning Revolution [J]. Journal of Beijing Radio and TV University, 2013, (6).

[4] Yang LIU. Zhenzhong HUANG. Yu ZHANG. Manli LI.A Survey Report on the Participation of Chinese MOOCs Learners [J]. Educational Research of Tsinghua University, 2013, 34 (4).

[5] Lin JIANG. Xibin HAN. Study on Characteristics and Learning Effects of MOOCs Learners [J]. NCET, 2013, (11).

[6] Ry Rivard. Is American Open Education Export a "Cultural Invasion"? [J] Journal of Seeking Knowledge Guide, 2013, (2).

[7] Jiangang CHENG. Dialectical Analysis of MOOCs and Thinking about the Development of Online Education, Sina Education

[8] Xiaoqing GU. Yiling HU. Huiying CAI. Localization of MOOCs and its Countermeasures [J]. Journal of Distance Education, 2013, (5). 